\title{
MARX Y EL DERECHO MODERNO *
}

Es imposible tratar de exponer los principios generales de un análisis marxista del derecho sin señalar previamente ciertas deformaciones que sufrió, durante mucho tiempo, la teoría marxista del derecho. Estas deformaciones no son especificas de dicha teoría pues forman parte de corrientes teóricas generales en la historia del pensamiento marxista que interpretaron de manera errónea a Marx. Si bien es cierto que Marx en ninguna parte trata del derecho de manera sistemática, o sea como objeto especifico de investigación teórica, no es menos cierto que su teoría nos proporciona algunos principios para esa investigación. De este modo, las deformaciones de la teoría marxista del derecho, considerando la relación del derecho y del Estado y la importancia política de este último objeto teórico, reflejan directamente las deformaciones teóricas y políticas del pensamiento marxista en general.

No es cuestión de hacer aquí un inventario de esas deformaciones sino de trazar sus lineamientos generales. Sin embargo, como toda lectura de la historia de un pensamiento procede de principios de lectura, me inclinaré a dar esos lineamientos exponiendo el contenido original del pensamiento marxista que precisamente nos proporciona las claves de un desciframiento sistemático de la historia de sus variaciones deformadoras.

En efecto, se puede trazar el esquema de la historia de la teoría marxista del derecho localizando sus oscilaciones entre una tendencia que se puede caracterizar como "economista" y otra caracterizada como "voluntarista". No me extenderé en estas dos tendencias sobre las que insiste Cerroni en su artículo del

- Este artículo está reproducido, de acuerdo a las disposiciones legales vigentes, del libro Hegemonía $y$ dominación en el Estado moderno, Ed. Pasado y presente, Córdoba, 1969. presente número de los Archivos, sino que me limitaré a trazar sus lineamientos principales. (1)

La primera, representada de manera muy característica por Stuchka y Pashukanis, opera una "reducción" del nivel jurídico a la instancia económica. Esta tendencia, a pesar del valor teórico de un autor como Pashukanis, de alguna manera considera al derecho como un reflejo inmediato de la "base" económica. Para Pashukanis más particularmente, el derecho privado consiste en un orden de relaciones sociales imitado de las relaciones de los poseedores de mercancías. Se asemeja a una concepción puramente instrumentalista de las superestructuras, que ve en ellas un elemento de la estructura social directamente determinado por la base económica, de la que se limita a seguir sus meandros y caminos, más o menos fielmente, como simple apéndice. La consecuencia teórica de esta tendencia es que el sistema jurídico no aparece en ella como un objeto especifico, teóricamente construído, de investigación científica. $\mathrm{Pa}$ recería que lo que está implícitamente cuestionado por esos autores es la posibilidad de una teoría marxista del derecho relativamente autónoma de las otras ramas de la teoría marxista. $Y$ esto a pesar de saber que la posibilidad de una teoría particular está basada en la autonomía y la especificidad de su objeto; no en la realidad social empírica - hecho admitido por Pashukanis a propósito del derecho- sino como objeto constituido por esta teoría en objeto de investigación teórica. Una teoría marxista del derecho sólo tiene validez en la medida en que constituye su propio objeto. Bajo este aspecto, no sería exagerado ver en Pashukanis y Stuchka la continuidad de la tendencia teórica "economista" de la Se-

1 Para las obras de Pashukanis y de Vyshinsky, me baso en la antología de Hazard: Soviet legal philosophy, 1951. 
gunda Internacional, según la cual el marxismo, siendo una teoria general de las sociedades y de la historia, se reduciría a una "ciencia de lo económico". En Karl Korsch (2) hay una exposición descriptiva de las consecuencias de esta concepción para las investigaciones marxistas en el dominio de las ciencias sociales.

La segunda tendencia, voluntarista, está representada por autores tales como Reisner y Vyshinski. El derecho es considerado como un conjunto de normas emitidas por el Estado, que encarna la voluntad de la clase dominante. (3) Esta tendencia de constitución de un objeto teórico, en este caso el universo jurídico considerado como un conjunto normativo, está ligada a toda una concepción errónea de las superestructuras y de su relación con lo económico. La base económica, concebida en forma mecanicista, consistiría en un campo inerte "accionado" por la voluntad y la conciencia humana. El princ:pio de la relación entre lo económico y el sistema jurídico está representado por un sujeto creador de las normas jurídicas, a partir de las "condiciones" de la base. A su vez, éstas se presentan, en tanto que forma de conciencia social, como "actores" del sistema en su conjunto, concepción que está, menos paradojalmente de lo que pueda parecer, en relación directa con el pen-

2 Ver su reseña del libro de Pashukanis en Archiv für die geschichte des Sozialismus und der Arbeiterbewegung, año 1930.

3 “... Reisner y Vyshinsky consideraron a las normas jurídico-estatales como datos-hechos, las "redujeron" de alguna manera colocándolas entre paréntesis en tanto que "objetos normativos", separándolas así de los valores concretos que expresan. Todo universo de normas, de mandatos prácticos, presupone una cristalización -explícita o no en ese universo- de valores en función de los cuales se estructura la jerarquía normativa. El carácter particular de aquellos dominios de la superestructura que constituyen un conjunto normativo, la moral, la religión, el derecho y el Estado, el mismo arte (aunque en otro sentido) reside precisamente en el hecho de que expresan el deberser social. Esos dominios son así genéticamente estructurados $y$ deben ser metodológicamente captados en función de los valores históricos concretos, engendrados a partir de la base, que encarnan. Dicho de otro modo, la condición de existencia de una regla o institución de nivel jurídico-estatal reside en los valores históricos que especifica jurídicamente, en la medida en que esos valores, en un contexto histórico dado, han revestido ese modo particular de ex- samiento de Lukács en Historia y Conciencia de ciase. La consecuencia teórica de esta tendencia es que el derecho es constituido como objeto teórico autónomo de investigación sólo en la medida en que está en relación genética con un sujeto creador histórico - voluntad de clase- de ese objeto. Sin embargo, aunque es verdad que un objeto teórico no puede de ninguna manera ser reducido a la historia de la génesis de un objeto real, esta tendencia de la teoría marxista del derecho no está dirigida a un objeto científico sino a un objeto ideológico. Ninguna relación científica puede ser basada así entre lo económico $y$ el universo jurídico, $y$ no es casual que los textos de Vyshinski no contengan ninguna indicación útil referida al derecho, en oposición a los textos de Pashukanis. Si el empirismo y el pragmatismo de Pashukanis son la causa de que fracase su proyecto (la constitución de una teoría marxista del derecho), el idealismo de Vyshinski sitúa su investigación en un vacío, en una ausencia de objeto cientifico que no es otra cosa que la omnipresencia de un objeto ideológico.

La tendencia de Vyshinski converge además en una teoría marxista que consiste en lo que puede designarse como una "superpolitización" del objeto de investigación. Al estar la constitución de este objeto referida a un sujeto de su génesis sujeto de la sociedad y de la historia (en este caso la clase o voluntad

presión que es el campo jurídico. Las nociones mismas de regla, norma o institución jurídicas, en tanto que realidades históricas y objetos de análisis, no son genéticamente captadas y son, pues, operatorias sólo en la medida en que son axiológicamente concretadas. Para esto, no es suficiente con poner, a imitación de Reisner y Vyshinski, esas normas en relación inmediata $y$ desde el exterior -en tanto que objetos ya estructurados- con la lucha de clases, limitando su contenido axiológico a su carácter de hecho como "normas-tendientes-a-la aplicación-de-las-clases- oprimidas". Explotación, por cierto. ¿pero por mediación de qué valores concretos? ¿Cómo, por ejemplo, los valores actuales de igualdad y de libertad (que precisamente, en tanto que valores, hacen aparecer al Estado como un "orden superior" de conciliación de los diversos intereses) actúan como fuerzas de explotación y en qué sentido esta explotación reviste, en razón también de esos valores, un carácter particular?" (Poulantzas, Nicos, "La teoría marxista del Estado y del derecho..." en Hegemonía y dominación..., p. 13; N. del E.) 
de clase) todo nivel de estructura social es reducido a su significación política considerada como su causa de existencia. El corto circuito entre el objeto teórico y la realidad histórica operado por la identidad politica-histórica y expresado por la emergencia del objeto ideológico, repercute en el estatuto de la teoria: se trata de la expresión "ciencia burguesa-ciencia proletaria" cuyo representante típico en la teoría del derecho es Vyshinski. La teoria marxista en general se convierte así, en última instancia, en una "ciencia de la revolucióm".

Sin embargo, localizar esas deformaciones de la teoría marxista, y en particular de la teoría marxista del derecho como variaciones de la temática "voluntarismo-economismo" es sólo el primer paso hacia su lectura. Lo que interesa, en efecto, es ver cómo esas variaciones son sólo las expresiones de una misma invariante. Lo que sumariamente se ha caracterizado como tendencia "economista" y "voluntarista" son en realidad dos caras de una misma moneda, dos expresiones de una misma problemática ideológica. Si sus conclusiones parecen diametralmente opuestas, es sólo porque sus principios, idénticos, implican esta variación continua. Esa problemática -el orden interno que rige las cuestiones planteadas por una teoría a su objeto- es la de una cierta interpretación de la obra de Marx. Implícita con frecuencia en las obras en cuestión, se encuentra en realidad en el propio Marx. Es la problemática del joven Marx. No quiero decir con esto que los autores que nos interesan hayan tenido conocimiento, o se inspiren conscientemente, en las obras de juventud de Marx, sino que esta problemática, relativa en su núcleo a las relaciones entre Hegel y Marx, consiste en una cierta concepción teórica acerca del punto de partida real de Marx y de qué es lo que abandonó definitivamente en sus obras de madurez. Este problema es particularmente importante para la teoría marxista del derecho. En sus obras de juventud Marx se ocupó sistemáticamente de los problemas referidos al campo jurídico $y, \sin$ embargo, no se puede extraer de allí nada referido a un fundamento científico de la teoría marxista del derecho.

Esta problemática puede ser caracterizada como una problemática historicista del sujeto. ¿Cuáles son sus caracteres generales? Los diversos niveles del conjunto de la estructura social, y sus relaciones, están fundados en su origen genético por un sujeto creador de la sociedad y principio unilineal, en su autodesarrollo, de la historia. Esos niveles forman una "totalidad" en la medida en que se supone que son engendrados por un centro, constituyendo todo nivel una "pars totalis", una simple expresión de ese sujeto central. Dicho de otro modo, las diversas realidades sociales son consideradas como si tuviesen un sentido en tanto que manifiestan, bajo formas y apariencias variadas, una esencia. Se reconocen aquí los elementos característicos de la teoria hegeliana, en la que el Espíritu absoluto ocupa el lugar de sujeto central. La transposición de esta problemática en el marxismo reviste diversas formas: ese sujeto puede estar representado ya sea por la "clase social", o por la "praxis", o también por un cierto nivel de la estructura social, en este caso por lo económico. Tomemos este último ejemplo por ser significativo. Considerando la relación Marx-Hegel bajo la metáfora de "trastocamiento" en el sentido de que Marx habría puesto de pie la dialéctica de Hegel, lo económico, la "base", recibe el lugar que ocupa en Hegel, el Espíritu: es el sujeto central de la estructura social, detentando las claves de la inteligibilidad de esta estructura. Cada nivel puede así ser explicado sólo como expresión de lo económico. Sin embargo, este lugar de sujeto central puede ser ocupado por otros principios, por ejemplo la "praxis". Las relaciones de los diversos niveles de la realidad social están fundadas en su reducción a un principio de origen genético -la praxis - que sería su denominador común en tanto que principio de génesis de su sentido. Para resumir esta problemática podríamos decir que una estructura social y las relaciones de sus niveles son reducidos a un sujeto central, desempeñando necesariamente la investigación científica el papel de una historiografia de la génesis, en un proceso de esencia a existencia, de las distintas expresiones fenoménicas a partir de esta esencia central.

¿Cuáles son las consecuencias de esta problemática? En primer lugar, una imposibilidad de investigación teórica concerniente a los diversos dominios de la superestructura. Volvamos a la tendencia economista: las superestructuras no pueden ser consideradas en su autonomía relativa y su eficacia especifica. Sólo tienen sentido como expresión de lo económico. Se insistirá en vano sobre su autonomía, se destacará el hecho de que hay una "acción recíproca" de la base y de la superestructura. Lo que aparece como viciada es la relación misma entre la base y las superestructuras. La acción de la superes- 
tructura sobre la base será considerada como el impacto externo y accidental de una excrecencia sobre el tronco que la engendró. La autonomía relativa de un nivel superestructural no estará fundada en la especificidad de sus estructuras propias, dado que esas estructuras se ordenan sólo como un reflejo de la instancia central, sino como producto de una deformación, en su sentido más riguroso, del autodesarrollo lineal de esta instancia. Estará basada en la concepción de la autonomía de las superestructuras calcadas del esquema de una historicidad simple de los orígenes, sobre su "retraso" o "adelanto" con respecto de ese sujeto central que los engendra, en este caso lo económico. En última instancia, tal autonomía será una astucia de la historia.

En segundo lugar, no se pueden descubrir relaciones entre la base y las superestructuras. Esto es tan cierto que en ese sentido sólo puede hablarse de relaciones entre dos térm:nos, ambos constituidos en tanto que tales en y a través de su relación; entre dos términos a los que su relación precisamente los constituye en su especificidad y autonomía. $\mathrm{Si}$, por el contrario, esta relación está referida a un sujeto central que sería el origen de esos términos, la relación deviene identidad ( $y$ no unidad). Tal identidad resulta de la absorción de un término por el otro, o de su reducción en el interior del sujeto central que manifiestan. En la tendencia voluntarista aparece claro que la clase sujeto, la voluntad de clase, constituye implícitamente el sujeto originario a la vez del derecho y de la estructura económica, en este caso de la estructura económica por "mediación" del derecho. Su relación está basada en el hecho de que serian los productos del mismo principio originario, de la voluntad de una clase.

Se ve ya esbozarse el terreno teórico común del voluntarismo y del economismo: la base económica y la voluntad de clase, en este caso bajo su aspecto de productora de las superestructuras, ocupan a su turno el lugar del sujeto central de la "historia". Se trata, en realidad, de un sucederse, de una totalidad circular que implica un desplazamiento constante del centro de gravedad, pero siempre en el mismo círculo. Si es lo económico lo que ocupa este lugar, las superestructuras sólo pueden aparecer alli como simples apéndices. En consecuencia, aunque no se quiera poner el acento en las superestructuras, esto sólo es posible a condición de un tras- tocamiento que desplace el centro hacia las superestructuras. Por el contrario, si son las superestructuras las que ocupan este lugar, aunque no se quiera poner en evidencia la importancia de lo económico esto sólo es posible a condición de un desplazamiento simétrico, que atribuya ese papel a lo económico. El aspecto economista existe en la tendencia voluntarista, así como el aspecto voluntarista en la tendencia economista. Lo que interesa es que la problemática en cuestión permite esa continua transmutación, en la medida en que las relaciones de homología y de circularidad, que caracterizan sus conceptos de totalidad y de historia, hacen lícitas esas transmutaciones de papel y más aún, las implican. El economismo y el voluntarismo son las dos variables, teóricamente coexistentes, de una misma invariable que es la concepción historicista del sujeto.

Por otra parte, esta es precisamente la concepción del joven Marx quien, criticando a Hegel mediante la reversión, yendo de lo abstracto idealista a lo concreto materialista, permanece prisionero de la problemática hegeliana expuesta anteriormente. En resumen, la crítica de Hegel por Marx está hecha sobre el modelo feuerbachiano. En el joven Marx el lugar del sujeto es detentado por los "individuos concretos-hombre genérico", esencia de la sociedad. Los niveles de la superestructura, en este caso el derecho y el Estado, son considerados según el modelo de la alienación. Constituyen fenómenos ilusorios y falsos, mistificaciones cuya única función es ocultar la esencia de la realidad social que consistiria en el hombre genérico-individuos concretos. El Estado y el derecho se identifican aqui con la ideologia que opera como un fenómeno alienante. Esta es la concepción "humanista" del marxismo que continúa actualmente haciendo estragos entre los investigadores marxistas.

Por el contrario, el Marx de la madurez abandona esa concepción de una esencia del hombre como principio central de la sociedad y de la historia para referirse a estructuras. Con ello, opera en realidad una verdadera ruptura teórica con sus concepciones de la juventud abandonando definitivamente la problemática historicista del sujeto. Esta ruptura se esboza ya en la Ideología Alemana y se consolida en 
el Prólogo a la Contribución a la crítica de la economía política. (4)

En efecto, para el Marx de la madurez, una estructura social, un modo de producción o una formación social, consiste en un conjunto de niveles con estructuras propias y eficacia específica, con predominio, en última instancia, de lo económico. La unidad de una formación social o de un modo de producción no está de ningún modo referida a una contradicción simple y originaria -la contradicción económica Capital/Trabajo- produciendo, en su auto-desarrollo de esencia a existencia, los diversos momentos-niveles-elementos en una equivalencia circular. La unidad social es siempre compleja en el sentido de que las estructuras económicas, como dominantes en última instancia, sólo pueden ser loralizadas en el interior de esta unidad. Sus otros niveles, digamos las superestructuras, no son el simple producto de lo económico-sujeto, sino, en su propia especificidad, las condiciones de existencia vigentes de lo económico. Los diversos niveles superestructurales intervienen no secundariamente sino originariamente en una estructura social global. Sólo en el interior de tal estructura lo económico puede ser localizado como elemento dominante en última instancia. Se puede de ese modo caracterizar el tipo de unidad marxista de un modo de producción o de una formación social como "estructura con dominante" (structure á dominante). Debido a que el tipo de unidad marxista que caracteriza al conjunto es una estructura de las características de las señaladas, el predominio en última instancia de lo económico sólo existe como reflejo, en el interior de un conjunto, de niveles específicos, siendo éstos condición de existencia de aquél y aquél condición de existencia de éstos. En resumen, decir que en una cierta estructura lo económico es predominante en última instancia, es indicar que ocupa tal lugar sólo en función de la especificidad y de la eficacia propia de los otros niveles que constituyen la estructura social como unidad compleja. Es también indicar que esta especificidad y eficacia propia es función de la unidad compleja ordenada por el reflejo en otros niveles del predominio en última instancia de lo económico. Lo económico no constituye

4 Me refiero aquí a los textos de Louis Althusser: Pour Marx [hay edic. cast: La revolución teórica de Marx, Siglo XXI, México, 1966] y Lire le Capital, t. I y II, París, 1965, así como mi artículo "Vers une théorie marxiste", en Les Temps Modernes, mayo 1966. así un sujeto central cualquiera de la unidad. Esta unidad consiste en un descentramiento de los diversos niveles, en un desplazamiento originario de las instancias de un todo complejo en el interior del cual lo económico detenta el predominio en última instancia.

Estas observaciones nos conducen a concluir que la especificidad y la eficacia propias de un nivel particular de la estructura -digamos el derecho- no depende de su naturaleza, sino de su ubicación y de su función en un tipo de relaciones de los niveles en el interior de una unidad compleja. Tampoco las relaciones entre los diversos niveles de estructuras y prácticas sociales pueden ser tematizados simplemente como una acción reciproca de la base y de la superestructura, como relaciones externas entre niveles cuya especificidad es eliminada por simple reducción del uno al otro, o entre niveles que se consideran especificos pero que aparecen como ya constituidos en su heterogeneidad y exterioridad. Su especificidad y su eficacia propias dependen de su ubicación y función en una unidad global. Sin embargo, dicha unidad sólo está ordenada por el reflejo concreto en su esqueleto del predominio en última instancia de lo económico.

Evidentemente, se trata aquí del problema del modo de determinación, por medio de lo económico, de la especificidad y de la eficacia propia de los diversos niveles en el interior de una estructura social de conjunto. En efecto, es tan peligroso creer que lo económico se caracteriza por una misma naturaleza en toda unidad social, como que su predominio en última instancia reviste en toda unidad la misma forma. En lo que concierne más particularmente a este último punto, toda estructura social está caracterizada por una "matriz" específica, por un tipo particular de articulación de las diversas instancias y niveles que depende del modo particular que reviste alli el predominio en última instancia de lo económico. Ese modo puede hacer, por ejemplo, que el "papel dominante" en el conjunto de una estructura social sea detentado por otra instancia que no sea lo económico, digamos por el derecho o el Estado. Ocurre que el predominio concreto en última instancia de lo económico se refleja aquí a través del desplazamiento del papel dominante a otro nivel. Este es frecuentemente el caso de numerosas formaciones sociales. Marx nos indica por ejemplo en El capital, a propósito de lo ideológico, que es la ideologia -la reli- 
gión- quien tiene con frecuencia el papel dominante en las formaciones feudales. Observa, sin embargo, que en esas formaciones es precisamente to económico lo que hace que lo ideológico revista el papel dominante.

Esto nos conduce a precisar los conceptos de modo de producción y de formación social.

Por modo de producción se designará no lo que se indica en general por instancia económica, las relaciones de producción en sentido estricto, sino un sistema de combinaciones específicas de las diversas instancias o niveles que allí constituyen otras tantas estructuras regionales de ese modo. El modo de producción, como lo dice de manera esquemática Engels, comprende diversos niveles de estructura o de instancias: lo económico, lo político (la superestructura del Estado y del derecho), lo ideológico y teórico. El tipo de unidad que caracteriza, para el marxismo, un modo de producción, es el de un todo complejo de niveles de estructuras con dominante, en última instancia, de lo económico. Esto no significa que lo económico ocupe siempre el lugar dominante, sino que lo económico es determinante en última instancia porque determina a aquel nivel que ocupa el papel dominante en un modo de producción dado, constituyendo una unidad con dominante. Lo que diferencia a un modo de producción de otro, lo que especifica la "matriz" de un modo de producción, es el tipo particular de articulación $y$ de relaciones que mantienen los diversos niveles, en ese todo complejo con dominante. Dicho de otro modo, hablar de un "modo de producción" determinado es descubrir la manera particular en que se refleja, en el interior de éste, el predominio en última instancia de lo económico, reflejo que determina el tipo de articulación que caracteriza ese modo. En esta perspectiva, la especificidad de los diversos niveles de un modo de producción, no estando ya esos niveles determinados por su naturaleza sino por su ubicación y su función en la totalidad compleja, sólo puede ser estudiada por su localización, en tanto que instancias regionales, en el interior de la matriz de ese modo.

Sin embargo, el "modo de producción" constituye un concepto que exije un examen "teórico" de la combinación "pura" de los niveles y del sistema de las formas. Una formación social históricamente determinada, en la realidad "histórica" y en tanto que forma de individualidad histórica, presenta una com- binación particular de varios modios de producción teóricamente establecidos en su "pureza". Esta formación social presenta una unidad compleja con dominante, en la medida en que, entre los diversos modos de producción que la componen, un modo particular detenta el papel dominante. Se trata aqui de una formación social históricamente determinada por un modo de producción dado. El predominio de ese modo de producción en la formación social en cuestión, hace que la matriz de ese modo de producción, sea la reflexión particular del predominio en última instancia que la especifica, deje su impronta en el conjunto de la formación, impregnándolo de la matriz del modo de producción dominante. En ese sentido, una formación social históricamente determinada es especificada por un tipo particular de articulación y de predominio de sus niveles o instancias económicas, políticas, juridicas, que es, por regla general, teniendo en cuenta diversos desajustes, el del modo de producción dominante. $Y$ esto en la medida exacta en que la unidad compleja con dominante (manifiesta en la formación social por el predominio de un modo de producción sobre los otros) es debida, en tanto que "tipo" de unidad característica de una formación, a la unidad compleja con dominante en última instancia de lo económico, que caracteriza el tipo de unidad del "modo de producción" dominante.

Detengámonos aquí en dos series de reflexiones concernientes por una parte a los problemas de métodos, y por la otra al problema que plantea el concepto de historia en el marco de una teoría marxista del derecho.

En primer lugar, es evidente que proceder al examen científico del nivel jurídico de un modo de producción dado, supone como premisa teórica localizarlo como nivel particular en el tipo de articulación y de relaciones de niveles que especifica un modo de producción "puro". En ningún caso se puede comenzar la investigación con una concepción general de lo que es el derecho, a riesgo de descubrir las formas particulares o el contenido diferencial que reviste en los diversos modos de producción. La demarcación teórica de un objeto de investigación -el derecho en este caso-, la definición misma de ciertas estructuras y prácticas como jurídicas, depende del 
lugar y de la función que revisten en un modo complejo teóricamente definido que constituye un modo de producción especificado. En resumen, si bien se conoce en general que todo modo de producción comprende ciertos niveles con predominio en última instancia de lo económico, si bien se conoce una cierta disposición de lugares, en cambio no se conoce nada sobre los ocupantes de esos lugares, sobre las estructuras específicas de los diversos niveles, de modo tal que no se ha definido teóricamente el todo compiejo que distribuye esos lugares, que rige las relaciones de los niveles $y$, de ese modo, sus estructuras.

En ese sentido, asi como se trata de construir teóricamente el todo complejo de un modo de producción, para una teoría marxista del derecho se trata también de construir teóricamente el concepto de su objeio especificado. Me detengo en esto porque creo que es un problema muy importante. Esta operación científica distingue la teoría marxista de toda investigación fundada en "modelos", "esquemas" o "tipos ideales". Para esta última, esos "modelos" o "tipos ideales" residirían en una relación "abstracto-concreto", "ideal-real", "objeto de conocimiento-real empírico" que se origina en una problemática empirista y positivista del conocimiento. En el caso por ejemplo del "tipo ideal" de Max Weber su producción consiste en una localización de los desajustes diferenciales de muchos fenómenos "reales" pertenecientes al mismo tipo "abstracto". El valor operatorio de ese "tipo" está asegurado por su aptitud para aclarar lo "real concreto" de los fenómenos que se presentan como otros tantos desajustes de ese tipo "abstracto". Esta concepción del objeto de conocimiento, del objeto teórico como esquematización de lo real, finalmente como simple generalización y abstracción, surge precisamente de una concepción empirista del conocimiento que no puede reconocer una autonomia propia de la teoría como nivel particular de las estructuras y prácticas sociales. Implica el postulado de una armonía preestablecida entre "abstracto" y "real", residiendo la abstracción tipológica en una adecuación asintótica, aunque necesaria, con el real concreto del que sería extraída. Por el contrario, para la problemática marxista de la teoría, se trata de producir el concepto de una instancia regional de un modo de producción no mediante la "abstracción" a partir de los fenómenos "reales concretos" de una formación social, sino mediante el proceso de construcción teóri- ca del concepto de ese "modo de producción" y del tipo de articulación de las instancias que lo especifican. El resultado de la ciencia de los modelos o de los esquemas es llegar, en oposición con la teoria marxista, a nociones que no pueden dar cuenta del objeto específico de una ciencia particular. En efecto, este objeto no es lo "real concreto" esquematizado, sino un concepto teóricamente construído.

Hemos visto las aporías de las tendencias economista y voluntarista de la teoría marxista del derecho en lo que concierne a sus principios metodológicos referidos a la teoría del conocimiento: ausencia de objeto especííico en Pashukanis (empirismo positivista), objeto ideológico (idealismo especulativo) en $\mathrm{Vy}$ shinski. En realidad, sus desacuerdos concernientes a ese problema de las relaciones de la teoria y de su objeto se relacionan a su problemática general del historicismo del sujeto. Para esta problemática, el status de la teoría, del conocimiento científico, reside finalmente en el descubrimiento, mediante el proceso de auto-desarrollo histórico, de su esencia, lo que quiere decir en ese caso develación de sus origenes y auto-conciencia de su génesis. En la corriente economista, esto se manifiesta en la concepción del objeto de conocimiento como "reflejo". Asi como el nivel real del derecho es considerado como genéticamente engendrado por lo económico-sujeto, el derechoobjeto de conocimiento es el "reflejo" del derecho real, o sea, en realidad, una imagen del "real concreto" económico. En la corriente voluntarista, el derecho-objeto de conocimiento no es sino la voluntad de clase-sujeto que lo engendró, en resumen la aprehensión de su origen histórico, de la esencia, cuyo fenómeno constituye. La relación profunda de esas posiciones es la siguiente: la teoría y su objeto son reducidas al sujeto histórico supuesto, la teoría se convierte en una teoría de la historia y la historia en una historia de la teoría; la investigación teórica en una búsqueda de los orígenes y una historiografía de la génesis; el objeto teórico en una emergencia en el campo epistemológico de la esencia del sujeto, ya sea de lo histórico empírico concreto (lo económico), o de lo histórico especulativo (voluntad o conciencia de clase).

Aquí se halla precisamente el núcleo de las deformaciones señaladas del marxismo: en el concepto de historia que esas concepciones implican. Sería muy largo entrar a tratar el fondo del problema. Me limito a señalar que la concepción marxista original de 
la historia se distingue radicalmente de una concepción historicista que la reduce a un desarrollo lineal de tipo cronológico. La construcción del concepto de un objeto de investigación teórica (el derecho moderno por ejemplo) no consiste en la investigación de sus antecedentes "históricos" ni en la de sus orígenes. La historia del derecho no consiste en una investigación de cierto desarrollo lineal de lo "jurídico" cuyo presente nos daría las claves de comprensión de su pasado, cuya actualidad sería el desarrollo o la degradación de su esencia. Se trata de construir conceptos del derecho siguiendo los diversos modos de producción en el interior de los cuales está previamente localizado. Si es verdad que en su autonomía y especificidad lo jurídico puede ser el objeto de una investigación histórica particular, esta última está subordinada a la construcción teórica de esos conceptos. Dicha construcción permite descifrar su historicidad propia, sus ritmos diferenciales siguiendo las formaciones sociales consideradas y el orden de sus sucesiones y transformaciones en el proceso real. Habría que cuidarse de emplear, a propósito de esos conceptos-objetos de investigación, el término teórico-históricos pues revela una ambigüedad capital. En efecto, no se trata de construir esos conceptos en medio de una generalización y abstracción a partir del derecho tal como existe concretamente en las formaciones sociales, a partir de una "realidad" que poseería en sí una inteligibilidad histórica, sino a partir de una construcción teórica de los diversos modos de producción cuya coexistencia y lucha sirven de base al proceso de transformación de las formas de que habló Marx.

A la luz de un concepto del derecho semejante, de una investigación teórica semejante, se puede aclarar el nivel jurídico concreto de una formación social histórica. Ya que una formación social real está caracterizada por una coexistencia histórica de varios modos de producción definidos en su pureza teórica, el nivel jurídico de una formación consiste en una coexistencia concreta de varios "derechos" pertenecientes teóricamente a los diversos modos de producción coexistentes. Sin embargo, lo que predomina por regla general en el nivel jurídico, es el derecho perteneciente al modo de producción dominante en esta formación. También el examen, en su "impureza" histórica, del nivel jurídico de una formación - por ejemplo de una formación capitalista, o sea de una formación con dominante del modo capitalista de producción- supone previamente la construcción teórica de los diversos modos de producción coexistentes y de los diversos tipos teóricos de derecho que les coresponden. Propiamente hablando, el examen de lo jurídico en una formación social dada en la realidad histórica, procede de diversos conceptos de derecho así construidos.

Esta complejidad de la estructura de una formación social, que implica varios niveles con historicidades propias, no permite además descifrar los desajustes históricos que pueden existir entre las estruciuras de esos niveles. Ya se ha visto que estos desajustes, considerados por el historicismo como acontecimientos excepcionales, fueron tematizados como "avances" o "retrocesos" de la estructura juridica en relación a la estructura económica. Esta es implícitamente reconocida como detentando las claves de una historicidad lineal que dirigiria el conjunto de una formación. Vista la autonomía relativa y el ritmo propio de los diversos niveles, esos desajustes, debidos, al desarrollo desigual de las diversas estructuras, son el fundamento mismo de su existencia histórica. Dicho de otro modo, esos desajustes "históricos" de lo jurídico en relación con lo económico no constituyen avances o retrocesos de la estructura del derecho sobre la estructura económica. Forman parte de una misma estructura, que es la del conjunto de una formación social históricamente determinada con niveles que poseen historicidades propias y cuyo desarrollo desigual es función de esta estructura misma.

Después de estas observaciones, podemos hacer algunas consideraciones generales referentes al examen marxista del derecho en el modo de producción capitalista. Si bien es cierto que Marx no nos da en El Capital un análisis del nivel jurídico de ese modo, tampoco es menos cierto que en esa obra expone el tipo de articulación que lo especifica y nos da así los principios de una investigación similar.

Yo diría muy esquemáticamente que ese tipo particular de articulación de los niveles que caracteriza el modo capitalista de producción reside en la autonomización específica que alli revisten sus diversas instancias. En efecto, si sólo se consideran los tres niveles que nos interesan más particularmente, el económico (relaciones de producción) el político (el Estado) y el jurídico, se comprueba que en las formaciones precapitalistas se presentan como estrechamente imbricados. Imbricación de lo económico y de lo político, de lo económico y de lo jurídico, de lo po- 
lítico y de lo jurídico caracterizan el ethos antiguo o los privilegios feudales. El modo de producción capitalista está especificado, por el contrario, por una autonomización característica, o sea una especificidad estructural propia, de lo económico y de lo político (separación de lo económico y de las estructuras del Estado), de lo económico y de lo jurídico (derecho moderno).

Ese tipo de articulación del conjunto de la estructura del modo capitalista de producción, está ligada a la combinación específica que caracteriza las relaciones de producción capitalistas. Depende por lo tanto de la forma concreta que alli reviste el reflejo del predominio en última instancia de lo económico. Observemos más detenidamente: las relaciones de producción consisten en general en formas de combinación entre ciertos elementos constituídos por el trabajador (el productor directo), los medios de producción (objetos y medios de trabajo) y el no-trabajador que se apropia del trabajo excedente. Lo que es importante señalar, más particularmente en el caso de un análisis de lo jurídico, es que la combinación entre esos elementos no consiste en una simple relación de propiedad (propietario no trabajador) o de nopropiedad (productor directo) jurídica de los medios de producción. Consiste en una doble relación, una relación de propiedad jurídica de los medios de producción -que Marx designa como propiedad y que proviene de la superestructura- y una relación que Marx designa algunas veces como propiedad, pero más frecuentemente como "posesión" o "apropiación real" y que distingue claramente de la primera. (5) Esta concierne más particularmente a una relación específica del productor directo -del trabajador-y de los medios de producción que es una relación realmente económica que designa to que se puede caracterizar como la posibilidad para el productor directo de introducir en el proceso de reproducción los medios de producción. $E$ insisto en este punto pues originó una serie de discusiones en la teoria marxista. Al no distinguir las dos relaciones, se tiende a identificar la relación jurídica de propiedad con la relación económica de la apropiación real. (6)

5 Ver al respecto el texto capital de Balibar: "Les concepts fondamentaux du materialisme historique", en Lire le Capital, t. II.

6 En la discusión marxista teórica, este problema se plantea de la siguiente manera: ¿la relación de propiedad es una relación económica?
Lo fundamental es que, según Marx, en los modos pre-capitalistas de producción, aunque estén caracterizados por formas de propiedad que instauran una separación jurídica del productor directo y de los medios de producción, la relación realmente económica de posesión o de apropiación real consiste en una noseparación del productor directo y de los medios de producción. Como Marx lo expresa en los Grundrisse, no hay todavía separación del productor directo y de las "condiciones naturales del trabajo". En el caso del esclavo y del siervo, esos productores directos están "ligados" a la tierra por toda una serie de nexos "mixtos", económicos, jurídicos y políticos, independientemente de la propiedad de la tierra que pertenece a los propietarios terratenientes. Esta no-separación en la relación de posesión se mantiene todavía en la manufaciura. Por el contrario, en la gran industria del modo capitalista de producción, se asiste a una separación de productor director de los medios de trabajo en el marco de la posesión, caracterizándose el modo capitalista de producción precisamente por una correspondencia entre la propiedad juridica -la separación en el marco de la relación jurídica- y la separación en el marco de la apropiación real.

Esas observaciones capitales, por otra parte, sólo pueden despertar reminiscencias al teórico del Derecho. Son harto conocidos los problemas que a partir del derecho romano se plantearon a propósito de la "posesión", radicalmente distinta de la prop:edad, a propósito de este "infra-derecho", de este "estado de hecho" cuya emergencia en el campo de lo jurídico dio lugar a tales controversias. Lo que interesa señalar aquí es que la no-separación del productor directo $y$ de los medios de próducción en la apropiación real de los modos precapitalistas de producción da lugar a una estructura social "mixta" caracterizada por una estrecha imbricación de lo económico, lo jurídico y lo político. Marx lo expresa de ese modo en El capital indicando paralelamente que esa relación profunda es el fundamento oculto de las superestructuras En todas las formas "en que el trabajador directo es 'poseedor' de los medios de producción y de las condiciones de trabajo necesarias para la producción de sus propios medios de subsistencia, la relación de propiedad juridica debe manifestarse a la par como relación directa de dominio y servidumbre... En estas condiciones, sólo la coacción extraeconómica, cualquiera que sea la forma que revista, puede arrancar a estos productores el trabajo sobrante para el terrate- 
niente... La relación directa existente entre los propietarios de los medios de producción y los productores directos... Es la que nos revela el secreto más recóndito, la base oculta de toda la construcción social y también, por consiguiente, de cada forma específica de Estado. (7)

En el texto capital de los Grundrisse zur Kritik des politischen Okonomie, más particularmente en la parte titulada "Formaciones económicas precapitalistas". Marx expone los diversos tipos de propiedad jurídica de los modos de producción correspondientes que varían siguiendo las formas que reviste la no-separación del productor directo y de los medios de producción en el marco de la apropiación real. Esas formas tienen algo de común: consisten en tipos particulares de no separación $y$, en consecuencia, de imbricación estrecha de lo económico, lo jurídico, y lo político. Esto se manifiesta en el hecho de que las relaciones de propiedad (jurídica) y de apropiación real -posesión- (económica) tienen por presupuesto teórico la pertenencia de los agentes de la producción a una comunidad política.

Un agente sólo es propietario o poseedor de esos medios en la medida en que es, previamente, miembro de esta comunidad. Marx dirá por ejemplo que el elemento común de las formas de propiedad y de apropiación de los modos de producción precapitalistas asiático, antiguo, germánico, etc., caracterizados por esta no-separación, es el siguiente. "La actitud ante la tierra, ante la tierra como propiedad del individuo que la trabaja, significa que un hombre se presenta desde el comienzo como algo más que la abstracción de "individuo que trabaja", presentándose como un modo objetivo de existencia en su propiedad de la tierra, modo que precede a su actividad y no aparece como su simple consecuencia y tiene tanto de condición previa de su actividad como su piel y sus sentidos, pues en el proceso vital se desarrollan, reproducen... la piel y órganos sensoriales... que también son presupuestos por éste. Lo que inmediatamente media esta actitud es la existencia del individuo como miembro de una comunidad". (8) Las formas jurídicas y los tipos de Estado varían siguiendo las formas específicas que reviste esta no-separación. (9) En el

7 El capital, edic. cit., t. III, p. 732-733.

8 "Formaciones económicas precapitalistas", en El modo de producción asiático, op cit. p. 14.

9 Ibid. p. 5. modo de producción asiático, son las comunidades particulares las poseedoras de la tierra, propiedad del Estado. Esto corresponde al hecho de que "la unjdad omnicomprensiva que está por encima de todas estas pequeñas comunidades puede presentarse como el más elevado y el único propietario, siendo las comunidades reales tan sólo poseedores hereditarios". Así "es perfectamente posible que ella aparezca como algo separado y superior a las numerosas comunidades concretas y específicas... Aquí el déspota aparece como el padre de todas las numerosas comunidades menores, realizando así la unidad común de todas". (10) En el modo de producción antiguo, el agente de producción es propietario privado pero en tanto que miembro de la comunidad política: "Ser miembro de la comunidad sigue siendo la condición previa para la apropiación de la tierra, pero en su capacidad de miembro de la comunidad el individuo es un propietario privado... Pero esta "pertenencia" está mediada por su existencia como miembro del Estado, a través de la existencia del Estado; y por lo tanto a través de una condición que es considerada como divina". (11) La diferencia entre el hombre libre y el esclavo no es aquí, en primer lugar, una diferencia entre propietario y no-propietario de los medios de producción sino una diferencia entre miembros de la comunidad política $y$ aquellos que no lo son. En el caso particular de la forma de propiedad germánica, Marx nos muestra dicha forma política en estos términos: "Entre los germanos, con jefe independiente de familias que se establecen en los bosques, separados por grandes distancias, incluso desde una perspectiva externa la comunidad sólo existe en virtud de cada acto de unión de sus miembros, si bien su unidad existente en si misma está encarnada en la prosapia... Por esto la comunidad se presenta como una asociación y no como una unión, como un acuerdo cuyos sujetos independientes son los terratenientes y no como una unidad. De hecho, pues, la comunidad no tiene existencia como Estado, como entidad politica según ocurría entre los antiguos... Para que la comunidad ingrese a la existencia real, los terratenientes libres deben celebrar una asamblea, en tanto que en Roma, por ejemplo, existe con prescindencia de esas asambleas". (12) Esos análisis de los Grundrisse son además completados por análisis semejantes referidos al

10 Ibid. p. 5.

11 Ibid. p. 7.

12 Ibid. p. 12 
modo de producción feudal -accidentalmente tratado aqui- en el tercer libro de El capital, en el capítulo sobre la génesis de la renta de la tierra.

Es importante observar que en las relaciones que tienen como condición teórica la no-separación del productor directo de los medios de producción, o sea una relación de no-separación hombre-naturaleza en el caso de los modos de producción fundados en la preponderancia de la agriculiura, los agentes de la producción sólo entran en las relaciones de producción y en relaciones de "propiedad" en tanto que pertenezcan, como presupuesto, a una unidad "política". Dicho de otro modo, la forma de individualidad de los agentes de la producción es su pertenencia a una comunidad "mixta", económica y jurídico-política. Esto es válido en primer lugar para los agentes de producción-propietarios, pues sólo son propietarios en tanto que miembros de la comunidad política. $Y$ también es válido para los productores directos no-propietarios (o simples poseedores). Estos son no-propietarios en la medida precisamente en que son, o bien excluídos de la comunidad política o bien tienen un status público específico en esta comunidad. Son poseedores en esa misma medida.

En el modo capitalista de producción, la separación del productor directo de los medios de producción en el marco de la relación de posesión o de apropiación real, implica una autonomización especifica de lo económico, de lo jurídico y de lo político. Esto se manifiesta en lo que se designa en general como "separación del estado y de la sociedad civil". En el caso de las relaciones de lo económico y de lo juridico, se manifiesta en el carácter sistemático del universo (con estructuras internas axiomatizadas) de reglas normativas que constituyen el derecho moderno y que lo distinguen radicalmente de las formas anteriores de lo jurídico. En el caso de las relaciones de lo jurídico y de lo político, aunque el caso sea aquí más complejo, se manifiesta en una autonomía relativa del derecho con respecto a la actividad propiamente política del Estado, cuya distinción en el interior de lo jurídico entre "derecho privado" y "derecho público" es sólo una de sus expresiones.

No es mi intención profundizar esos principios preliminares de la investigación: me limitaré así a señalar algunos puntos importantes que se prestan a confusión. Antes que nada, en el marco de esta autonomización de las instancias del modo capitalista de producción, ¿cuál es el modo de determinación de lo jurídico por lo económico? o, dicho de otro modo, ¿cuál es el modo en que se refleja el predominio en última instancia de lo económico a nivel del derecho? En realidad, este reflejo, la determinación de una estructura por otra, se manifiesta en ciertos límites que lo económico y la estructura global del modo de producción determinan a nivel jurídico, y en el interior de las cuales se ordena toda una serie de variaciones de lo jurídico debidas a su sistematicidad propia. En resumen, los efectos de una estructura (lo económico) sobre otra (lo jurídico) se manifiestan como limites que rigen las variaciones de esas estructuras pero también el modo de intervención de una estructura sobre otra. La intervención de lo económico sobre lo jurídico se ejerce a través de las estructuras propias de lo jurídico originadas a partir de los límites planteados por lo económico y el conjunto de la estructura de ese modo. Esa relación de límites y de variaciones no es, por otra parte, de ningún modo univoca: lo jurídico sirve también para determinar los límites de lo económico en el interior de una estructura de conjunto donde lo económico sólo se manifiesta como dominante en última instancia. Dentro de estos límites donde se plantea lo jurídico en lo económico tiene lugar la intervención de lo jurídico sobre lo económico. En El capital Marx presenta lo más claramente posible al derecho moderno como condición de existencia de lo económico en el modo capitalista "puro" de producción.

Traté de demostrar, además, cómo a partir del concepto de modo capitalista "puro" de producción, se puede construir el concepto teórico del derecho moderno como sistema con normas generales, abstractas, formales $y$ estrictamente reglamentarizadas en el sentido deque poseen una reversibilidad completa. (13) Dicho carácter había sido ya observado por Engels cuando indicaba que: "En un Estado moderno, el derecho no sólo debe corresponder a la situación económica general y ser la expresión de ésta, sino que debe ser también una expresión coherente y que no parezca, debido a contradicciones internas, palmariamente incon-

13 También he tratado de manera sistemática este problema en mi libro: Nature des choses et droit. Essai sur la dialectique du fait et de la valeur, París, 1965. Sin embargo, y esto tiene el sentido de una autocrítica, todavía estaba influenciado por el historicismo humanista del joven Marx. 
sistentes". (14) Haré aquí una sola observación; con demasiada frecuencia existe la tendencia a referir esos elementos del concepto teórico del derecho moderno a su única función en la reglamentación de los intercambios capitalistas (y no simplemente mercantiles). Es evidente que esas estructuras del sistema jurídico moderno se refieren a toda una serie de estructuras de lo económico, tanto a las de la circulación de las mercancias-intercambios (de la que forman parte el contrato de trabajo o compra-venta de la fuerza de trabajo), como a las de la distribución (vg. el reparto de los frutos del trabajo al que se refiere Marx en los famosos pasajes de la Critica del programa de Gotha) y a las estructuras del proceso de conjunto de la producción capitalista, por ejemplo a la calculabilidad y previsibilidad indispensabies para la reproducción ampliada que caracteriza el sistema capitalista y a las que Max Weber ya prestaba atención. Sin embargo, esas características del derecho moderno sólo pueden ser científicamente descifradas a partir de las "relaciones de producción" capitalistas en el estricto sentido definido más arriba, relaciones de producción que tienen además el predominio sobre las otras estructuras de lo económico.

Sólo mediante el estudio científico de esas relaciones de producción se puede descifrar el significado exacto de lo que Marx designaba como el surgimiento, dentro del modo capitalista de producción, del "individuo desnudo", del "propietario privado" y del "trabajador libre". (15) Es conocida la importancia de todo esto en la estructuración del derecho moderno, reconocible no simplemente en nociones jurídicas tales ccmo "personas o sujetos de derecho". En realidad, el conjunto del sistema juridico moderno está estructurado con referencia, como principio exíerno de organización, a los agentes de producción en tanto que "individuos desnudos". Estos aparecen como el principio de ordenación de un universo de normas abstractas, generales, formales y estrictamente reglamentadas que rigen sus relaciones sociales. Dichos caracteres de las estructuras sistemáticas autonomizadas del derecho moderno tienen como punto de referencia una "atomización" e "individualización" específica de los agentes de la producción.

14 Carta a Conrad Schmit, del 27 de octubre de 1890. 15 "Formaciones económicas...", op. cit., pp. 25, 26, 33, 36-37, etc., así como en numerosos pasajes de El capital, en especial en el tomo I y en el t. III, capítulo sobre la "Génesis de la renta territorial".
Indudablemente esta cuestión provocó numerosas confusiones en la teoría marxista del derecho. Por una parte, se ha tendido frecuentemente a ver en este hecho un fenómeno ideológico, o sea una extrapolación engañosa segregada por el derecho moderno a fin de ocultar su carácter de clase. ¿Cómo se podría hablar de una atomización individualista de los agentes de la producción capitalista cuando se sabe fehacientemente que éstos sólo existen en las relaciones sociales como miembros de una clase social? Por otra parte, la tendencia humanista historicista del marxismo, adherida en ese caso a la concepción de los "individuos concretos" del joven Marx como sujetos de la sociedad y de la historia, ha terminado por ver en esos "individuos desnudos" el producto histórico real del desarrollo de la esencia del hombre genérico, el fundamento del derecho moderno que representaría la alienación o la reificación de esos individuos-hombres genérico.

Sin embargo, este problema podria dilucidarse mediante el análisis de las relaciones de producción capitalistas. Los "individuos desnudos" constituyen en primer lugar para Max los presupuestos teóricos del modo de producción capitalista; y digo los presupuestos teóricos pues se presentan también como condiciones históricas de ese modo por la disolución de las relaciones de producción feudales. Este último punto, sin embargo, revela en Marx una genealogía de los elementos del modo capitalista de producción, y se distingue netamente de su investigación teórica. Así, el "individuo desnudo" como presupuesto teórico de ese modo, tanto en los Grundrisse como en El Capital está ligado precisamente a la separación del productor directo de los medios de producción en el marco de la apropiación real de las relaciones de producción capitalistas; ello corresponde a lo que Marx mismo caracteriza como la autonomización mutua de los productores.

Esos "individuos desnudos" no son por elio simplemente un producto ideológico, a pesar de su extrapolación ideológica en el universo jurídico como "personas-sujetos", ni una simple forma de individualidad histórica de los agentes de producción capitalista, sino un presupuesto teórico del modo capitalista de producción y, de esa manera, del derecho moderno. Los "individuos desnudos" son la forma de individualidad que especifica a los agentes de la producción capitalista distribuidos en clases sociales modernas. Esto es lo que constituye la diferencia fun- 
damental entre las clases modernas. Es verdad que en la realidad histórica esos agentes de la producción funcionan como clases sociales, to que no impide que, en la construcción del concepto teórico del modo capitalista "puro" de producción, las clases sociales modernas impliquen "individuos desnudos" distribuidos en clases. Por otra parte, es erróneo ver en esos individuos realidades históricas-sujetos y fundamento del derecho moderno. Esto surge de la antropología económica del joven Marx. Por el contrario, el Marx de la madurez aprehende estructuras: los agentes de la producción -los "hombres"- no son el fundamento y el origen de las estructuras, sino su soporte. Los "hombres", en oposición a una concepción humanista, sólo aparecen en el Marx de la madurez como los portadores históricos de las estructuras. Esos "individuos desnudos" no son "hombres" históricos concretos sino formas teóricas que, constituyendo los presupuestos teóricos de las estructuras, son a la vez sus efectos. Los individuos desnudos aparecen teóricamente en "relaciones" estructuradas que son las relaciones de producción capitalistas "puras". Este análisis científico, y no una referencia a la obra juvenil de Marx, es lo que permite ver que el derecho moderno es un derecho de clase, aunque, y precisamente en la medida en que, la explotación y el dominio político de clase esté constantemente ausente de sus estructuras sistemáticas organizadas a partir de los "individuos desnudos".

Al terminar estas observaciones tan sumarias, esquemáticas y fragmentarias, querria concluir con la relación del Derecho y de la dominación política de clase, dejando sin embargo de lado el problema capital de las relaciones del derecho moderno y de las estructuras del Estado capitalista. En oposición a ciertas tendencias actuales que tratan de distinguir entre el "aporte científico" y el "tinte político" del marxismo, es evidente que el derecho moderno corresponde a la explotación de clase y a la dominación política de clase. La relación del derecho y de la dominación de clase no puede en ningún sentido ser reducida a la concepción de una voluntad de clase, sujeto creador del Derecho. Tampoco puede ser reducida a la sanción represiva que caracteriza las reglas jurídicas, en resumen, a un cierto papel indistinto de la violencia en la historia, a imitación de la concepción soreliana. El desciframiento de la relación constitutiva del Derecho y de la lucha de clases sólo puede ser científicamente establecida por su localización previa en el conjunto complejo de las estructuras de un modo de producción y de una formación. Precisamente esta localización es la que nos da las claves para la investigación de su relación con el campo de la lucha de clases. 